\title{
Dy-Fe-Sb (Dysprosium-Iron-Antimony)
}

\section{Raghavan}

An isothermal section at $500{ }^{\circ} \mathrm{C}$ for this ternary system was recently reported by [2008Liu], which depicts one ternary compound $\mathrm{FeDy}_{6} \mathrm{Sb}_{2}(\tau)$.

\section{Binary Systems}

The Dy-Fe phase diagram [Massalski2] has four line compounds: $\mathrm{Fe}_{17} \mathrm{Dy}_{2}\left(\mathrm{Ni}_{2} \mathrm{Th}_{17}\right.$-type hexagonal), $\mathrm{Fe}_{23} \mathrm{Dy}_{6}$ (D8 ${ }_{a}, \mathrm{Mn}_{23} \mathrm{Th}_{6}$-type cubic), $\mathrm{Fe}_{3} \mathrm{Dy}$ ( $\mathrm{Be}_{3} \mathrm{Nb}$-type rhombohedral), and $\mathrm{Fe}_{2} \mathrm{Dy}\left(C 15, \mathrm{MgCu}_{2}\right.$-type cubic). The Dy-Sb phase diagram depicts the following line compounds: $\mathrm{Dy}_{5} \mathrm{Sb}_{3}$ (D8 ${ }_{8}, \mathrm{Mn}_{5} \mathrm{Si}_{3}$-type hexagonal), $\beta \mathrm{Dy}_{4} \mathrm{Sb}_{3}, \alpha \mathrm{Dy}_{4} \mathrm{Sb}_{3}\left(D 7_{3}\right.$, $\mathrm{Th}_{3} \mathrm{P}_{4}$-type cubic), $\beta$ DySb, and $\alpha \mathrm{DySb}$ (NaCl-type cubic). The Fe-Sb phase diagram [Massalski2] has two intermediate phases: $\mathrm{FeSb}_{1-x}\left(40-48\right.$ at.\% $\mathrm{Sb} ; B 8_{1}$, NiAs-type hexagonal) and $\mathrm{FeSb}_{2}(C 18$, marcasite-type orthorhombic).

\section{Ternary Isothermal Section}

With starting metals of $99.9 \%$ Dy, $99.9 \% \mathrm{Fe}$, and 99.99\% Sb, [2008Liu] arc-melted under Ar atm 112 alloys, which were given a final anneal at $500{ }^{\circ} \mathrm{C}$ for 10-20 days and quenched in water. The phase equilibria were studied with $\mathrm{x}$-ray powder diffraction. They found that the binary compound $\mathrm{Dy}_{4} \mathrm{Sb}_{3}$ is not stable at $500{ }^{\circ} \mathrm{C}$ and decomposes after prolonged annealing. The isothermal section at $500{ }^{\circ} \mathrm{C}$ constructed by [2008Liu] is shown in Fig. 1. The ternary compound $\mathrm{FeDy}_{6} \mathrm{Sb}_{2}(\tau)$ is present. It has the $\mathrm{Fe}_{2} \mathrm{P}$-type of hexagonal structure, with $a=$ $0.81449 \mathrm{~nm}$ and $c=0.41641 \mathrm{~nm}$ [2007Zen]. No solubility of the third component in the binary compounds was observed.

\section{References}

2007Zen: L. Zeng, P. Qin, H. Qin, and J. Zhang, Crystal Structure and Magnetic Properties of the Compound $\mathrm{FeDy}_{6} \mathrm{Sb}_{2}$, Mater. Lett., 2007, 61(1), p 300-303

2008Liu: J. Liu, B. Zong, X. Yang, X. Cui, K. Su, X. Wang, and J. Li, The Isothermal Section of the Dy-Fe-Sb Ternary System at 773 K, J. Alloys Compd., 2008, 468, p 103-106

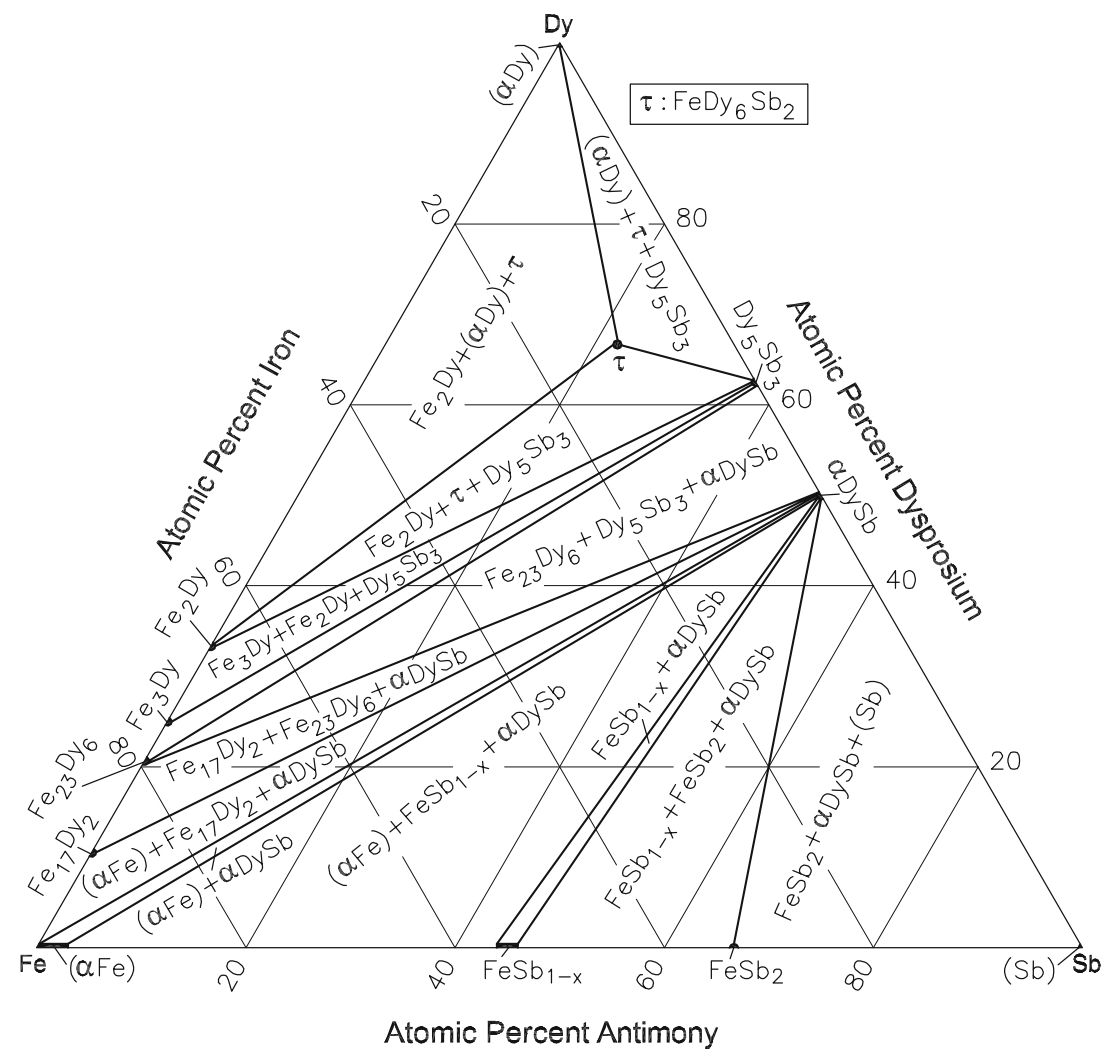

Fig. 1 Dy-Fe-Sb isothermal section at $500{ }^{\circ} \mathrm{C}$ [2008Liu] 